\title{
Postsynaptic Targeting of Alternative Postsynaptic Density-95 Isoforms by Distinct Mechanisms
}

\author{
Dane M. Chetkovich, ${ }^{1,2 *}$ Robert C. Bunn, ${ }^{1 *}$ Sheng-Han Kuo, ${ }^{1}$ Yoshimi Kawasaki, ${ }^{1}$ Minoree Kohwi, ${ }^{1}$ and \\ David S. Bredt ${ }^{1}$ \\ Departments of ${ }^{1}$ Physiology and ${ }^{2}$ Neurology, University of California, San Francisco, San Francisco, California 94143
}

\begin{abstract}
Members of the postsynaptic density-95 (PSD95)/synapseassociated protein-90 (SAP90) family of scaffolding proteins contain a common set of modular protein interaction motifs including PDZ (postsynaptic density-95/Discs large/zona occludens-1), Src homology 3 , and guanylate kinase domains, which regulate signaling and plasticity at excitatory synapses. We report that $\mathrm{N}$-terminal alternative splicing of PSD95 generates an isoform, PSD95 $\beta$ that contains an additional "L27" motif, which is also present in SAP97. Using yeast two hybrid and coimmunoprecipitation assays, we demonstrate that this $\mathrm{N}$-terminal L27 domain of PSD-95 $\beta$, binds to an L27 domain in the membrane-associated guanylate kinase calcium/ calmodulin-dependent serine kinase, and to $\mathrm{Hrs}$, an endosomal
\end{abstract}

Recent studies identify postsynaptic density-95 (PSD95) and other membrane-associated guanylate kinases (MAGUKs) as an important class of molecules that regulates assembly and function of postsynaptic protein networks (Kornau et al., 1997; Garner et al., 2000; Lee and Sheng, 2000; Tomita et al., 2001). PDZ (postsynaptic density-95/Discs large/zona occludens-1) domains from PSD95 cluster ion channels (Kim et al., 1995; Kornau et al., 1995), signaling enzymes (Brenman et al., 1996a), and cell adhesion molecules (Irie et al., 1997) at the PSD. PSD95 also contains Src homology 3 (SH3) and guanylate kinase (GK) domains that both mediate regulatory intramolecular interactions (McGee and Bredt, 1999; Shin et al., 2000) and recruit additional proteins to the macromolecular complex (Kim et al., 1997; Takeuchi et al., 1997; Brenman et al., 1998; Hanada et al., 2000). Through this network of interactions, PSD95 and related MAGUK protein complexes regulate postsynaptic development (El-Husseini et al., 2000b; Sala et al., 2001), plasticity (Guan et al., 1996), and convey retrograde signals (Scheiffele et al., 2000) to the presynaptic nerve terminal.

\footnotetext{
Received Feb. 8, 2002; revised April 24, 2002; accepted April 29, 2002.

This research was supported by grants from the Human Frontiers Science Program and the Christopher Reeves Paralysis Foundation (D.S.B) and from the National Institutes of Health (D.S.B. and D.M.C). D.S.B. is an established investigator of the American Heart Association. D.M.C. was a physician postdoctoral fellow of the Howard Hughes Medical Institute and is supported by a National Alliance for Research on Schizophrenia and Depression Young Investigator Award. R.C.B. was a postdoctoral fellow of the American Heart Association. We thank Drs. Lily Jan and Andrew Bean for antibodies to Kv1.4 and Hrs, respectively. We thank Dr. Mingjie Zhang and Roger Nicoll for comments on this manuscript and Michele Bondi for excellent secretarial work.

*D.M.C. and R.C.B. contributed equally to this work

Correspondence should be addressed to Dr. David S. Bredt, University of California at San Francisco School of Medicine, Box 0444, 513 Parnassus Avenue, San Francisco, CA 94143-0444. E-mail: bredt@itsa.ucsf.edu.

R. C. Bunn's present address: Arkansas Children's Hospital, Department of Endocrinology, 1120 Marshall Street, Little Rock, AR 72202.

Copyright (C) 2002 Society for Neuroscience $\quad 0270-6474 / 02 / 226415-11 \$ 15.00 / 0$
}

ATPase that regulates vesicular trafficking. By transfecting heterologous cells and hippocampal neurons, we find that interactions with the L27 domain regulate synaptic clustering of PSD95 $\beta$. Disrupting Hrs-regulated early endosomal sorting in hippocampal neurons selectively blocks synaptic clustering of PSD95 $\beta$ but does not interfere with trafficking of the palmitoylated isoform, PSD95 $\alpha$. These studies identify molecular and functional heterogeneity in synaptic PSD95 complexes and reveal critical roles for L27 domain interactions and Hrs regulated vesicular trafficking in postsynaptic protein clustering.

Key words: neuron; synapse; protein sorting; endosome; PSD95; Hrs
Because PSD95 participates in multitudes of interactions, it is unclear whether there are distinct classes of PSD95 protein complexes. Also uncertain are the sequence and hierarchy of interactions through which PSD95 assembles and clusters proteins at the PSD (Garner et al., 2000; Kennedy, 2000; Sheng and Sala, 2001). Developmental studies in cultured hippocampal neurons indicate that PSD95 traffics on the cytosolic surface of dendritic endomembranes (El-Husseini et al., 2000c) and clusters in dendrites before its interaction with synaptic glutamate receptors (Rao et al., 1998). Postsynaptic targeting involves endosomal sorting, because an endocytosis signal at the C terminus of PSD95 is required for proper trafficking (Craven and Bredt, 2000). The initial targeting of PSD95 to endomembranes and its subsequent postsynaptic clustering require palmitoylation of a pair of $\mathrm{N}$-terminal cysteines that are present in PSD95 (Craven et al., 1999) and its closest homolog, PSD93 (El-Husseini et al., 2000c). Cellular studies of other MAGUKs also suggest that targeting to the surface of endosomal membranes plays a general role in assembly of MAGUK protein complex (Thomas et al., 2000).

Here, we report that both rodents and human express two alternatively spliced isoforms of PSD95, a version containing the short palmitoylated $\mathrm{N}$ terminus that we designate PSD95 $\alpha$, and a form containing a longer $\mathrm{N}$ terminus, PSD95 $\beta$. Interestingly, the unique region of PSD95 $\beta$ is homologous to the $\mathrm{N}$ terminus of MAGUK protein, synapse-associated protein-97 (SAP97) (Muller et al., 1995). Furthermore, this region of homology between PSD95 $\beta$ and SAP97 has an unexpected similarity to a recently described protein-protein interaction motif, L27, named for its presence in PDZ proteins Lin-2 and Lin-7 (Doerks et al., 2000). And, the L27 domains in PSD95 $\beta$ and SAP97 bind to an N-terminal L27 domain in mammalian calcium-calmodulindependent serine kinase (CASK).

Despite lacking palmitoylation sites, PSD95 $\beta$ clusters efficiently 
at the PSD. Yeast two hybrid analysis shows that the L27 domains of PSD95 $\beta$ and SAP97 bind to Hrs, an endosomal ATPase that regulates protein sorting and has been implicated in vesicular endocytosis and exocytosis (Bean et al., 1997; Komada and Soriano, 1999; Urbé et al., 2000). A subpopulation of endogenous Hrs colocalizes with PSD95 in dendrites of hippocampal neurons. Furthermore, collapsing Hrs-positive early endosomes in hippocampal neurons selectively blocks postsynaptic clustering of PSD95 $\beta$ and SAP97 but does not disturb PSD95 $\alpha$, indicating distinct mechanisms for synaptic trafficking of alternative PSD95 isoforms. These studies demonstrate that alternative splicing contributes to the multitude of pathways and functions regulated by PSD95 at the synapse and identify possible roles for L27 protein domains and Hrs regulated vesicular trafficking in postsynaptic protein sorting.

\section{MATERIALS AND METHODS}

Antibodies. The human PSD95 $\beta \mathrm{N}$-terminal peptide corresponding to the second through sixteenth amino acids was synthesized with an added C-terminal Cys and coupled to maleimide-activated keyhole limpet hemocyanin, and rabbits were immunized using standard protocols (Zymed, South San Francisco, CA). Antibodies were affinity-purified on a Sepharose column to which the peptide was coupled.

The following primary antibodies were used: rabbit polyclonal antibodies to Kv1.4 (Kim et al., 1995) (provided by Lily Jan, University of California, San Francisco, San Francisco, CA), CASK (Zymed, South San Francisco, CA), sheep polyclonal antibody to PSD95 (Brenman et al., 1996b), guinea pig antibodies to green fluorescent protein (GFP) (ElHusseini et al., 2000a) and monoclonal antibodies to PSD95 (\#046; Affinity Bioreagents, Golden, CO), GFP (Beckton Dickson Biosciences, Palo Alto, CA), Hrs (initially provided by Andrew Bean, University of Texas Health Sciences Center, Houston, TX, and subsequently purchased from Alexis Biochemicals, San Diego, CA) and synaptophysin (Sigma, St. Louis, MO). The sheep and mouse PSD95 antibodies recognize both PSD95 $\alpha$ and PSD95 $\beta$ because they were prepared against the PDZ domains and are written as anti-PSD95(PDZ) in figures to distinguish them from the PSD95 $\beta$-specific antibody. For Western blotting, protein extracts were resolved by SDS-PAGE and transferred to polyvinylidene difluoride membranes. Primary antibodies were diluted in block solution containing $3 \%$ BSA, $0.1 \%$ Tween 20 in TBS and incubated with membranes overnight at $4^{\circ} \mathrm{C}$. Labeled bands were visualized using ECL (Amersham Biosciences, Piscataway, NJ).

cDNA cloning and mutagenesis. Constructs coding for PSD95 $\alpha$, SAP97, SAP102, MALS2, and CASK, as well as their GFP fusions have been previously described (Topinka and Bredt, 1998; Craven et al., 1999). PSD95 $\beta$ was generated by RT-PCR from human cDNA using the following primers: 5' TACGCCAAGCTTAAGCCACCATGTCCCAGAGACAAGA, and 3' GAGCTCGGTACCGGTATTTCTGACTCTCTGAGAGGGAAG. The resultant 165 bp fragment was inserted into Hind III, and a silent KpnI site introduced into PSD $95 \alpha$ in the mammalian expression vector, GW1 (El-Husseini et al., 2000a). N-terminal deletions of PSD95 $\beta$ were produced by PCR and inserted into the same sites. The N-terminal PSD95 $\beta$ yeast two-hybrid bait vector (pGBKT7-PSD95 $\beta(1-$ 53)) was produced by PCR amplification of the initial 159 base pairs of PSD $95 \beta$ and subcloning into pGBKT7 (Beckton Dickson Biosciences, Palo Alto, CA) at EcoRI/BamHI sites. A cDNA for Hrs, obtained from Dr. Andrew Bean (University of Texas Health Sciences Center, Houston, TX), was amplified by PCR and cloned into GW1 at HindIII-EcoRI sites. The proper introduction of all mutations and deletions was verified by DNA sequencing.

Northern blotting and in situ hybridization. RNA was isolated using the guanidine isothiocyanate-CsCl method, and mRNA was selected using oligo-dT Sepharose. For Northern blotting, mRNA was separated on a formaldehyde agarose gel and transferred to a Nylon membrane. The filter was sequentially hybridized with random-primed ${ }^{32} \mathrm{P}$ probes, which were generated using a 159 bp probe corresponding to the unique $\mathrm{N}$-terminal exons of PSD95 $\beta$. In situ hybridization used ${ }^{35} \mathrm{~S}$-labeled RNA probes was performed as described (Sassoon and Rosenthal, 1993). Antisense probes to the unique N terminus of PSD95 $\beta$ (1-159) or to the common coding region of PSD95 (nucleotides 1212-1444) were synthesized from Bluescript vectors. Tissue sections were exposed to x-ray film for $4 \mathrm{~d}$.
Yeast two-hybrid assays. Yeast two-hybrid assays were performed using the Matchmaker kit (Becton Dickinson Biosciences, Palo Alto, CA), according to the manufacturer's protocols. Briefly, PSD95 $\beta(1-53)$ was subcloned into the bait vector, pGBKT7. Yeast (AH109) were transformed with the bait vector under appropriate selection. A rat cDNA library in the prey vector, pGADT7 (Becton Dickinson Biosciences), was then screened by transformation into AH109 cells carrying bait plasmid and plated onto selective media. Colonies growing after $3-5 \mathrm{~d}$ were screened for $\beta$-galactosidase expression. Of 6 million colonies screened, 18 colonies growing on selective media were obtained. Two of these colonies were weakly positive for $\beta$-galactosidase activity, whereas one colony was strongly positive (clone 18.1). Plasmid was successfully isolated from the strongly positive colony, and sequencing revealed this clone to be a fragment of Hrs encoding amino acids 349-728. Directed yeast two hybrid assays were performed by cotransforming engineered plasmids into competent yeast followed by plating onto selective media.

Cell transfection, metabolic labeling, and immunoprecipitation. COS7 cells were grown in DMEM containing $10 \%$ fetal bovine serum, penicillin, and streptomycin. Cells were transfected using lipofectamine reagent according to the manufacturer's protocol (Invitrogen, Carlsbad, CA). For studies of palmitoylation, transfected COS7 cells were labeled in serum-free media containing $1 \mathrm{mCi} / \mathrm{ml}\left[{ }^{3} \mathrm{H}\right]$ palmitic acid $(50 \mathrm{Ci} /$ mmol; Perkin-Elmer Life Sciences, Boston, MA). Cells were washed with ice-cold PBS and resuspended in $0.4 \mathrm{ml}$ of lysis buffer containing TEE (50 mm Tris-HCl, pH 7.4, 1 mm EDTA, and 1 mm EGTA) and 150 $\mathrm{mm} \mathrm{NaCl}$. To this lysate was added $0.1 \mathrm{ml}$ of SDS-PAGE sample buffer lacking $\beta$-mercaptoethanol, and $10 \mu \mathrm{l}$ was loaded on $10 \%$ SDS-PAGE gels. For immunoprecipitation experiments, adult rat brains were homogenized in 10 volumes (w/v) of $50 \mathrm{~mm}$ HEPES, $\mathrm{pH} 7.5$, containing 10 $\mu \mathrm{g} / \mathrm{ml}$ aprotinin (Sigma, St. Louis, MO), $10 \mu \mathrm{g} / \mathrm{ml}$ leupeptin (Sigma), and $1 \mathrm{~mm}$ PMSF (Sigma). Nuclei were removed by centrifugation at $1000 \times g$. Crude membranes were obtained by centrifugation of the postnuclear homogenate at $100,000 \times g$ and were resuspended in $1 \%$ SDS in $50 \mathrm{~mm}$ Tris- $\mathrm{HCl}, \mathrm{pH} 7.5$. This step was followed by a 10 -fold dilution in buffer containing $1 \%$ Triton X-100. Samples were then incubated with $2 \mu \mathrm{g}$ of primary antibodies for $1 \mathrm{hr}$ at $4^{\circ} \mathrm{C}$. After addition of $20 \mu \mathrm{l}$ of Protein A-Sepharose beads (Sigma), samples were incubated for $1 \mathrm{hr}$ at $4^{\circ} \mathrm{C}$. Immunoprecipitates were washed four times with wash buffer containing TEE, $150 \mathrm{~mm} \mathrm{NaCl}$, and $0.1 \%$ Triton $\mathrm{X}-100$, boiled in SDS-PAGE sample buffer, and resolved by SDS-PAGE. For COS cell experiments, cells were lysed in TEE protease inhibitors, then incubated with primary antibodies and Protein A-Sepharose beads and resolved by SDS-PAGE as for brain lysates. For fluorography, gels were treated with Amplify (Amersham Biosciences) for $30 \mathrm{~min}$, dried under vacuum, and exposed to Hyperfilm-MP (Amersham Biosciences) at $-80^{\circ} \mathrm{C}$ for $12-24$ hr. Estimation of PSD95 $\beta$ relative abundance was performed by densitometric analysis of Western blots using the public domain NIH Image program (developed at the U.S. National Institutes of Health and available on the Internet at http://rsb.info.nih.gov/nih-image/.)

Primary neuronal culture and transfection. Hippocampal cultures were transfected as previously described (Craven et al., 1999). Briefly, acutely dissociated hippocampal neurons from E18 rats were transfected in suspension by lipid-mediated gene transfer based on the protocol described in (Kaech et al., 1996). Cells were then plated at a density of $600 / \mathrm{mm}^{2}$ on glass coverslips (Fisher Scientific, Pittsburgh, PA) and maintained in Neurobasal media supplemented with B27 (Invitrogen, Carlsbad, CA). For some experiments, neurons were transfected after 10-17 $\mathrm{d}$ in vitro using Effectene (Qiagen, Valencia, CA) according to manufacturer's protocols.

Immunofluorescent labeling. Coverslips were removed from culture wells and fixed in $2 \%$ paraformaldehyde for $15 \mathrm{~min}$ or in $100 \%$ ice-cold methanol for 10 min. After washing with PBS containing $0.1 \%$ Triton$\mathrm{X}-100$ (PBST) three times for 5 min, cells were incubated in PBST containing $3 \%$ normal goat serum for $1 \mathrm{hr}$ at room temperature. Primary antibodies were added in block solution for $1 \mathrm{hr}$ at room temperature, followed by donkey anti-mouse or goat anti-rabbit secondary antibodies conjugated to Alexa-488 (Molecular Probes, Eugene, OR) or Cy3 (Jackson ImmunoResearch, West Grove, PA) (diluted 1:200 in block solution) for $1 \mathrm{hr}$ at room temperature. Coverslips were then mounted on slides (Superfrost/Plus slides; Fisher Scientific) with Fluoromount-G (Southern Biotechnology Associates, Inc., Birmingham, AL). Images were taken under fluorescence microscopy with a $100 \times$ oil-immersion objective $(\mathrm{NA}=1.4)$ affixed to an Axiovert S100 TV inverted microscope (Zeiss, Thornwood, NY) equipped with a Hamamatsu 12-bit ORCA, interline CCD camera (Technical Instruments, San Francisco, CA), an 


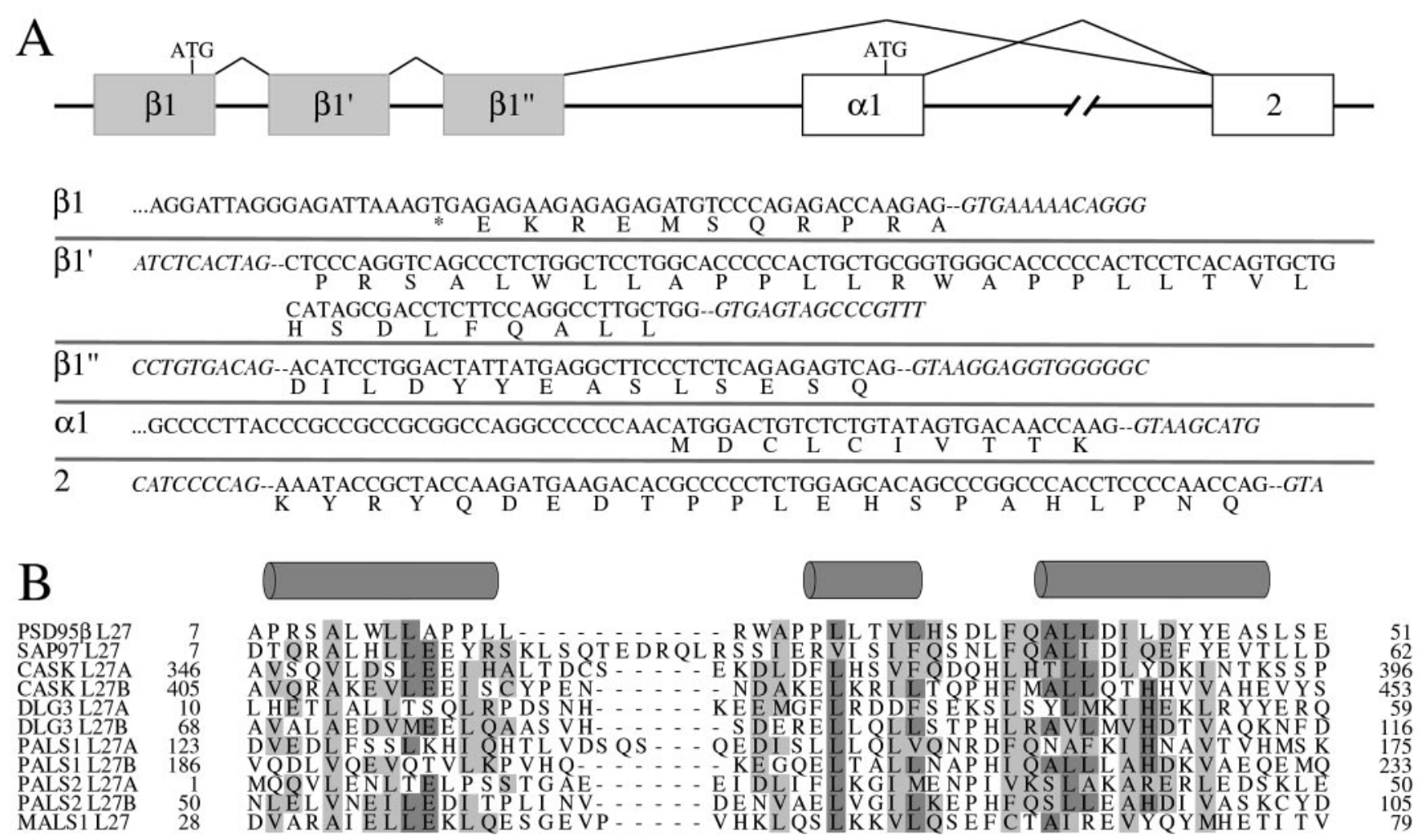

$\mathrm{C}$

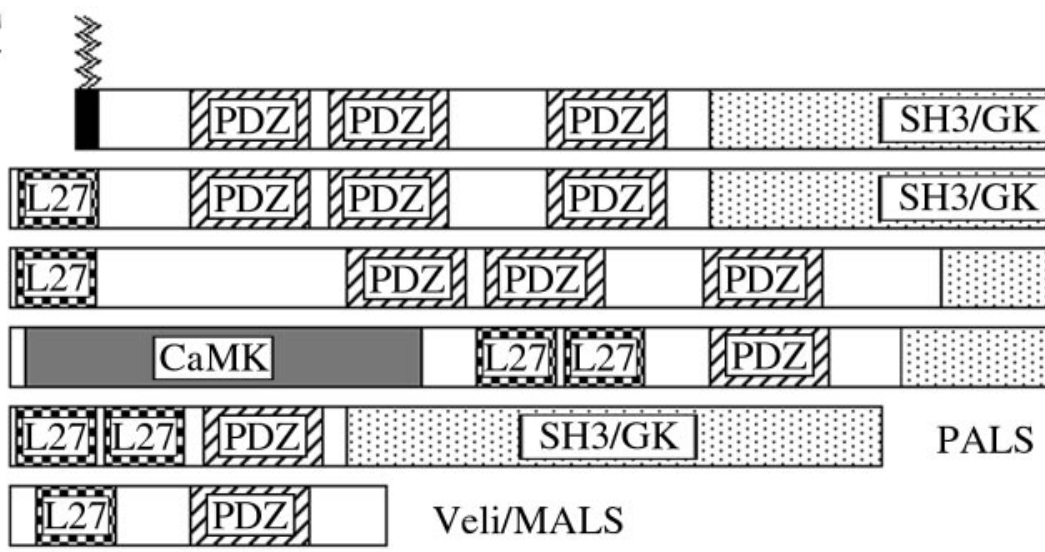

Figure 1. PSD95 $\beta$ and SAP97 contain N-terminal L27 domains. $A$, Scheme showing $5^{\prime}$ genomic structure of PSD95 (top). Three exons ( $\beta 1$, $\beta 1^{\prime}$, and $\left.\beta 1^{\prime \prime}\right)$ encode the N-terminal 53 amino acids of PSD95 $\beta$; immediately downstream is a single exon $(\alpha 1)$ that encodes the N-terminal 10 amino acids of PSD $95 \alpha$. These alternatively spliced isoforms of PSD95 splice into a common exon 2. The nucleotide and predicted amino acid sequences of these exons are shown (bottom); introns are in italics. B, Alignment of N termini of PSD95 $\beta$ and SAP97 with representative L27 domains. Identical residues are shaded darkly, and homologous residues are shaded lightly. Predicted helical regions underlie gray cylinders. $C$, Domain structures of PSD95 $\alpha$ and L27-containing proteins. Jagged lines denote N-terminal palmitates on PSD95 $\alpha$. Note that DLG3 has a similar domain structure as PALS (protein associated with Lin-7). CaMK, Calcium-calmodulin kinase domain.

excitation and emission filter-wheel (Sutter, Novato, CA), and a MetaMorph Imaging system (Universal Imaging Corporation, Downingtown, PA).

\section{RESULTS}

\section{PSD95 $\beta$ and SAP97 contain L27 domains that bind CASK}

Previous studies suggested that the extreme $\mathrm{N}$ termini of human and rat PSD95 proteins are different (Cho et al., 1992; Kistner et al., 1993; Stathakis et al., 1997). To analyze this difference, we compared the genomic sequences and found that both species contain exons that encode two isoforms in an organization that suggests alternative splicing (Fig. $1 A$ ). The $\mathrm{N}$ terminus of the shorter isoform, PSD95 $\alpha$, which contains two palmitoylated cysteines, is contained in a single exon encoding 10 residues that is upstream of exon 2. The larger $\mathrm{N}$ terminus of 53 residues in PSD95 $\beta$ is encoded by three exons that occur just upstream and are also spliced into the common exon 2.

Sequence analysis shows that the unique region of PSD95 $\beta$ shares $36 \%$ sequence identity with the $\mathrm{N}$ terminus of SAP97 (Fig. $1 B)$. This region of homology is not present in the other two 
paralogs PSD93/chapsyn-110 (Kim et al., 1996) and SAP102 (Muller et al., 1996). We searched the SMART protein domain database to determine whether the region of overlap between PSD95 $\beta$ and SAP97 resembles any known protein domain. Interestingly, significant homology was found to the "L27" motif, a 40-50 amino acid domain identified in PDZ proteins Lin-2 and Lin-7 (Doerks et al., 2000). L27 domains are predicted to have three acidic $\alpha$-helical segments (Doerks et al., 2000). Sequence alignment and secondary structural predictions indicate that the third predicted helical segment shows greatest homology to PSD95 $\beta$ and SAP97 (Fig. $1 B$ ).

L27 domains occur in several families of PDZ proteins (Fig. $1 C)$. They appear to form specific heterodimers and mediate interaction between Lin-2 and Lin-7 (Doerks et al., 2000). To determine whether the L27 domains in PSD95 $\beta$ and SAP97 share this functional property, we evaluated their binding to mammalian Lin-2 and Lin-7 homologs, CASK (Hata et al., 1996) and MALS/Veli (Butz et al., 1998; Jo et al., 1999), respectively. In transfected COS cells, the L27 domains of PSD95 $\beta$ and SAP97 bind selectively to CASK but do not bind to MALS2 (Fig. $2 A, B$ ). In brain, antibodies to PSD95 coimmunoprecipitate CASK, consistent with an interaction between CASK and PSD95 $\beta$ (Fig. $2 C$ ). CASK contains two L27 domains that occur in tandem between its calcium-calmodulin kinase and PDZ domains. We found that PSD95 $\beta$ and SAP97 bind selectively to the first L27 domain in CASK (L27A) whereas MALS2 binds to the second L27 domain (L27B) (Fig. 2D).

Previous cDNA cloning has isolated only PSD95 $\alpha$ from brain. To determine whether PSD95 $\beta$ is also expressed in brain, we performed Northern blotting, using a probe to the unique $\mathrm{N}$-terminal domain. This probe labeled a single band of $4.2 \mathrm{~kb}$ in poly $(\mathrm{A}+)$ mRNA from rat brain (Fig. 3D). In situ hybridization histochemistry was used to determine the cellular expression of PSD95 $\beta$. In sagittal sections of rat brain, PSD95 $\beta$ mRNA was found at high levels in a variety of neuronal populations (Fig. $3 A, B)$. Highest levels of PSD95 $\beta$ were detected in cerebellum, cortex, hippocampus, and corpus striatum. These neuronal localizations resembled closely those that contain PSD95 $\alpha$ (Fig. 3C). To evaluate the presence of PSD $95 \beta$ protein in the brain, we generated a polyclonal antibody against a peptide corresponding to amino acids $2-16$ of PSD95 $\beta$. In Western blots of crude brain extracts, this antibody detects a weak band of $97 \mathrm{kDa}$ that may correspond to PSD95 $\beta$; however, this required prolong exposure times (data not shown). To detect more sensitively PSD95 $\beta$ in brain, we immunoprecipitated brain homogenates with an antibody to the PDZ domains of PSD-95. We found that the PSD95 $\beta$ specific antibody readily detected a $97 \mathrm{kDa}$ band in these PSD95 immunoprecipitates (Fig. $3 E$ ). Furthermore, the PSD95 $\beta$-specific antibody immunoprecipitates an appropriately sized band, which is recognized by the anti-PDZ domain PSD-95 antibody (Fig. 3E). Quantitating the relative intensities of the bands using $\mathrm{NIH}$ Image revealed that PSD95 $\beta$ represents $\sim 10 \%$ of total PSD95 in brain.

\section{The L27 domain of PSD95 $\beta$ regulates synaptic clustering}

Previous studies have shown that N-terminal palmitoylation of the pair of N-terminal cysteines of PSD95 $\alpha$ determines receptor clustering (Hsueh et al., 1997; Topinka and Bredt, 1998) and postsynaptic targeting (Craven et al., 1999) of PSD95. We therefore wondered whether PSD95 $\beta$, which lacks N-terminal cysteines and is not palmitoylated (Fig. $4 A$ ), would still mediate
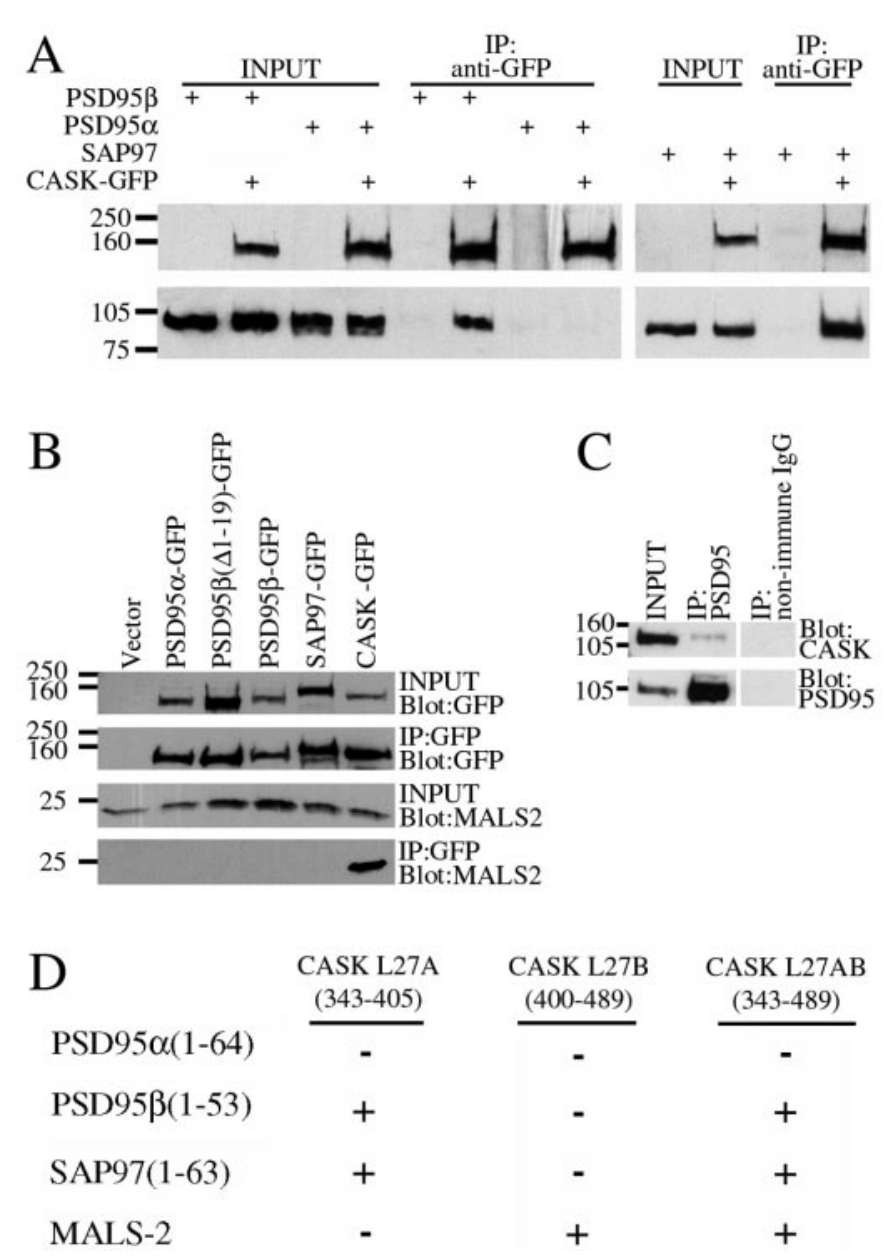

Figure 2. PSD95 $\beta$ and SAP97 can bind to CASK via L27 heteromultimerization. $A$, COS cells were transfected with PSD95 $\alpha$, PSD95 $\beta$, or SAP97 in the presence or absence of CASK-GFP, cell lysates were prepared, and CASK-GFP was immunoprecipitated with an antibody to GFP. Whereas PSD95 $\alpha$ showed no interaction with CASK-GFP, PSD95 $\beta$ and SAP97 coimmunoprecipitated with CASK-GFP. B, Lysates were prepared from COS cells cotransfected with MALS2 and PSD $95 \alpha-$ GFP, PSD95 $\beta$-GFP, SAP97-GFP, CASK-GFP, or empty vector. Western blotting after GFP immunoprecipitation shows that MALS2 binds only to CASK-GFP. C, Lysates were prepared from rat brain, and PSD95 was immunoprecipitated. Western blotting after immunoprecipitation shows that CASK binds to PSD95. D, Table showing domains of CASK that bind to SAP97, PSD95 $\beta$, or MALS2 by yeast two-hybrid assay. Yeast were transformed with plasmids encoding the $\mathrm{N}$ termini of MAGUK proteins or full-length MALS2 and L27 domains of CASK. MAGUK N termini and MALS were fused to the GAL4 DNA binding domain, and CASK L27 domains were fused to the GAL4 activation domain. Colonies that grew on plates lacking Leu, Trp, adenine, and His were scored as positives $(+)$.

these functions. To monitor ion channel clustering we transfected COS cells with PSD95 $\alpha$ or PSD95 $\beta$ together with Kv1.4. Whereas PSD95 $\alpha$ forms patch-like clusters on the surface of the cells together with Kv1.4 (Kim et al., 1995), PSD95 $\beta$ forms intracellular aggregates of both proteins in a perinuclear distribution (Fig. 4B). These intracellular aggregates resemble those formed when Kv1.4 is cotransfected with SAP97 (Kim and Sheng, 1996). To evaluate postsynaptic clustering, we transfected hippocampal neurons with PSD95 $\beta$ and compared distribution with that of a synaptic protein, synaptophysin. Surprisingly, despite lacking the N-terminal palmitoylated sites, PSD95 $\beta$ clustered efficiently at postsynaptic sites (Fig. $5 D-F$ ). To determine the region in 


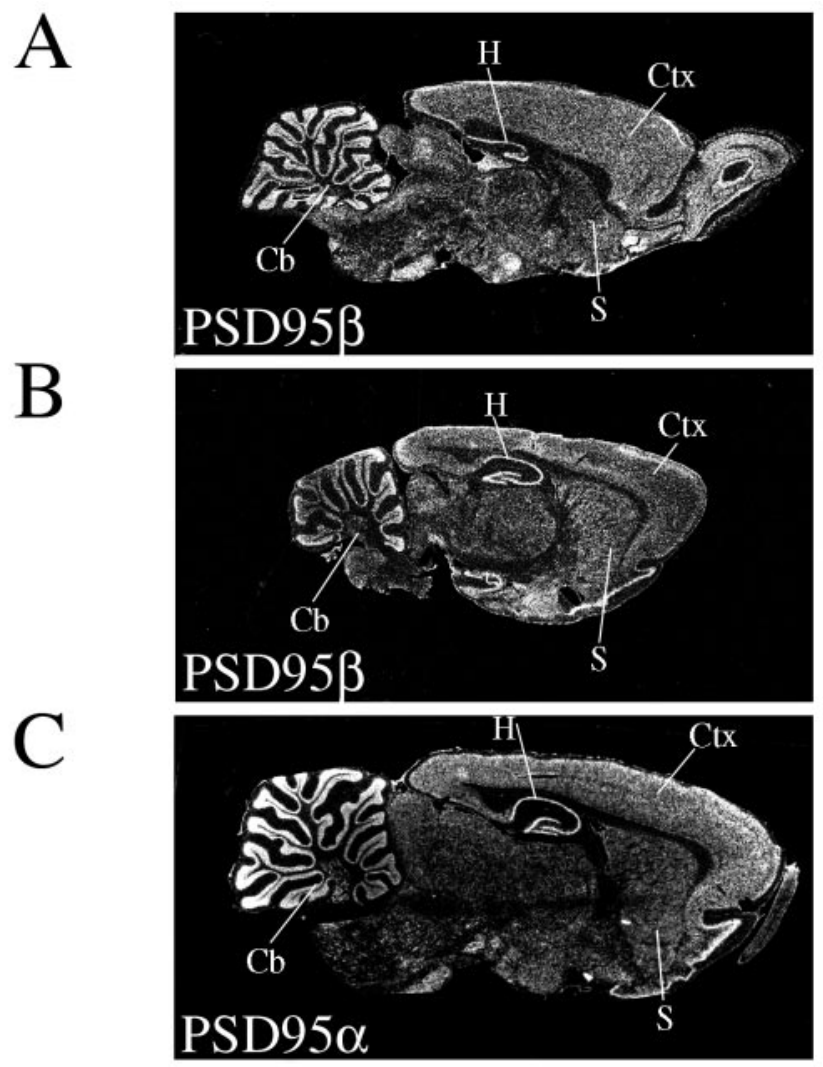

D

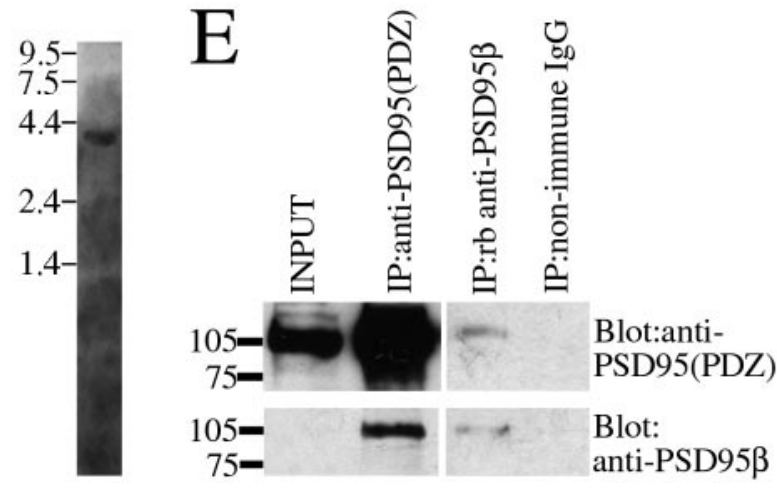

Figure 3. Expression of PSD95 $\beta$ in rat brain. $A-C$, In situ hybridization in sagittal sections of rat brain shows that PSD95 $\beta$ is expressed in diverse populations of neurons. Both PSD95 $\beta$ and PSD95 $\alpha$ occur at high levels in cerebellum $(\mathrm{Cb})$, hippocampus $(H)$, corpus striatum $(S)$, and cerebral cortex $(C t x)$. D, Northern blotting shows that the unique region of PSD 95 $\beta$ hybridizes to a single $4.2 \mathrm{~kb}$ band in poly $\left(\mathrm{A}^{+}\right)$RNA. $E$, Brain lysates were prepared and subjected to immunoprecipitation. A PSD95 $\beta$ specific antibody recognizes a $95 \mathrm{kDa}$ band in brain lysates immunoprecipitated with a general PSD95 antibody raised to the PDZ domains [anti-PSD-95(PDZ)]. Conversely, the PSD-95 $\beta$ antibody immunoprecipitates an appropriately sized band that is recognized by the general PSD-95(PDZ) antibody.

PSD95 $\beta$ that determines postsynaptic targeting, we transfected $\mathrm{N}$-terminal deletion constructs. We found that a construct lacking the first 19 residues was efficiently clustered, like PSD95 $\beta$, whereas a construct lacking the first 44 residues was diffusely expressed in the dendrites (Fig. 5G-L). These data indicated that residues between 19 and 44 are critical for postsynaptic targeting by the unique $\mathrm{N}$ terminus of PSD95 $\beta$.
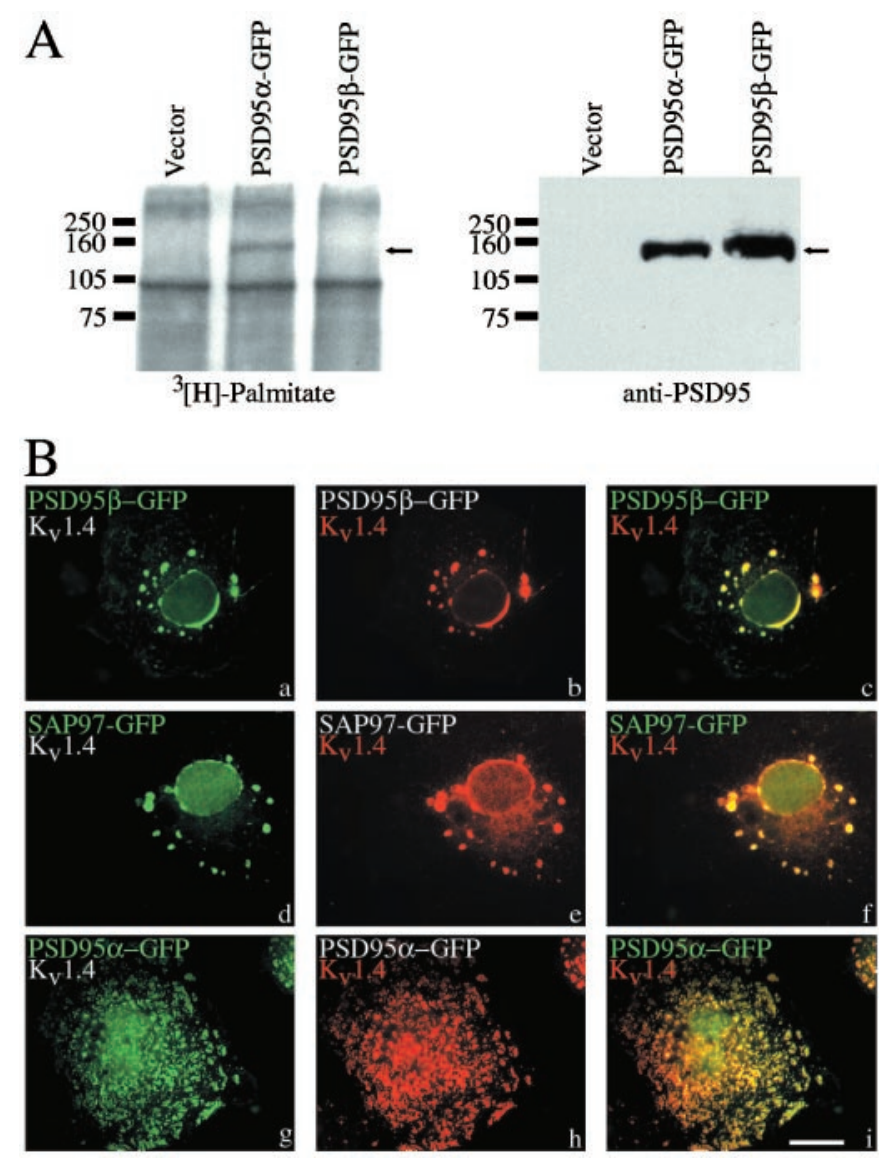

Figure 4. PSD95 $\beta$ is not palmitoylated and fails to form plasma membrane clusters with Kv1.4. $A$, COS cells were transfected with constructs encoding PSD $95 \alpha$ fused to GFP (PSD95 $\alpha-$ GFP), PSD95 $\beta-$ GFP, or empty vector, and were metabolically labeled with $\left[{ }^{3} \mathrm{H}\right]$ palmitate. Cells were then lysed, proteins were separated by SDS-PAGE, and gels were analyzed by autoradiography (left panel) or Western blotting (right panel). Arrows indicate the predicted molecular weight for PSD95 $\alpha-$ GFP and PSD95 $\beta$-GFP. $B$, COS cells were transfected with Kv1.4 and PSD95 $\beta$ GFP, SAP97-GFP, or PSD95 $\alpha$-GFP. Cells were fixed $48 \mathrm{hr}$ after transfection and labeled with antibodies to Kv1.4. When coexpressed with PSD95 $\beta$-GFP $(a-c)$ or SAP97-GFP $(d-f)$, Kv1.4 (red) accumulates on the nuclear membrane and on round perinuclear vesicles. In contrast, when transfected with PSD95 $\alpha-$ GFP $(g-i)$, Kv1.4 clusters in plasma membrane patches. Merged images are shown in panels on right $(c, f, i)$. Scale bar, $10 \mu \mathrm{m}$.

\section{The L27 domains of PSD95 $\beta$ and SAP97 bind Hrs}

Because postsynaptic targeting of PSD95 $\alpha$ requires palmitoylation-dependent association with endosomes (El-Husseini et al., 2000c), we wondered whether postsynaptic sorting of PSD95 $\beta$ also involves a vesicular trafficking pathway. To address this and to identify possible mediators, we screened a rat brain yeast two-hybrid library for proteins that interact with the first 53 residues of PSD95 $\beta$. Of $6 \times 10^{-6}$ clones screened, we obtained one clone that showed robust $\beta$-galactosidase activity. This clone was a fragment of Hrs, a FYVE finger protein that localizes to endosomes and regulates vesicular trafficking (Komada and Soriano, 1999). In addition to the FYVE domain, Hrs has VHS, coiled-coil, proline-rich and glutamine/proline-rich domains. The PSD95 $\beta$ interacting clone encoded the second coiled-coil domains as well as some $\mathrm{N}$ and $\mathrm{C}$-terminal flanking sequences (Fig. $6 A$ ). To map the region on Hrs that confers binding, we deleted residues from either the $\mathrm{N}$ - or $\mathrm{C}$ terminus. Deleting as few as 20 

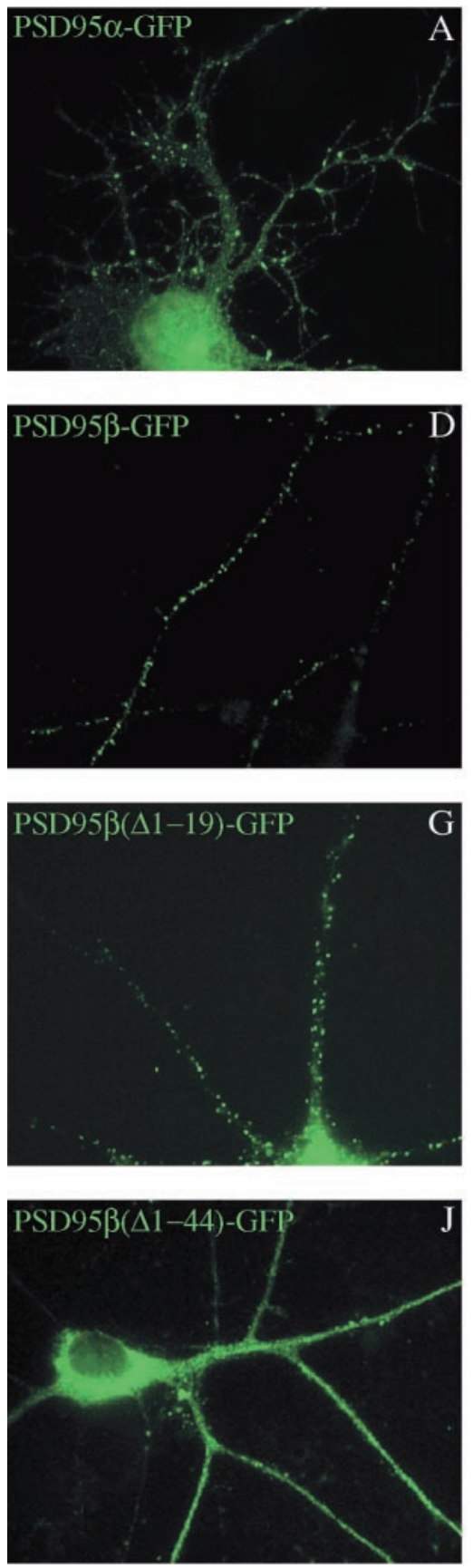
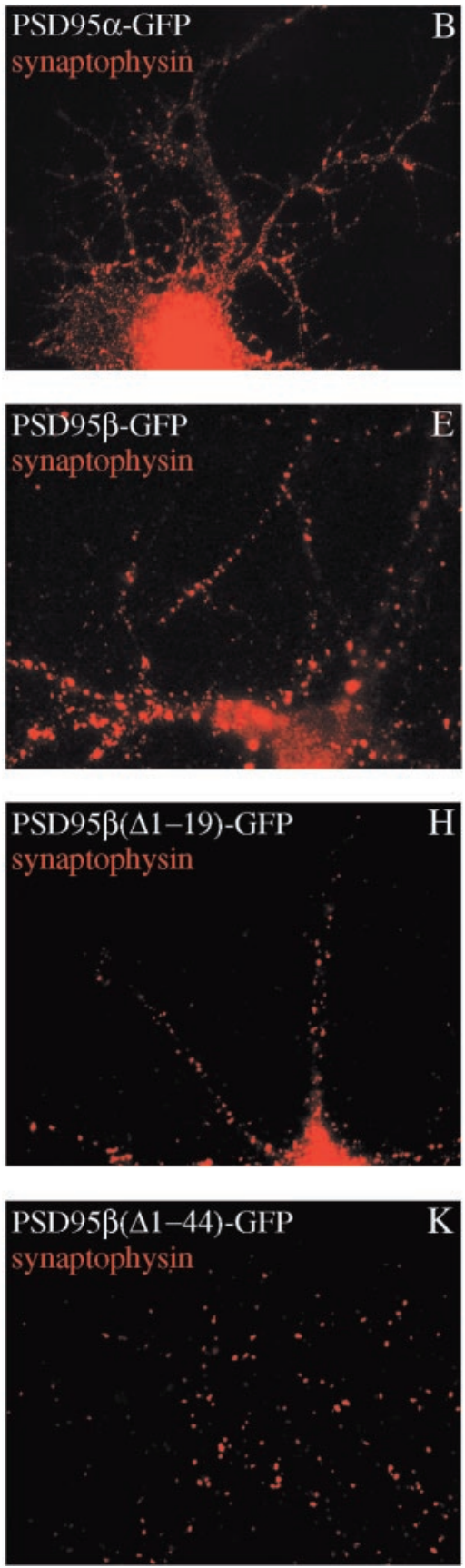
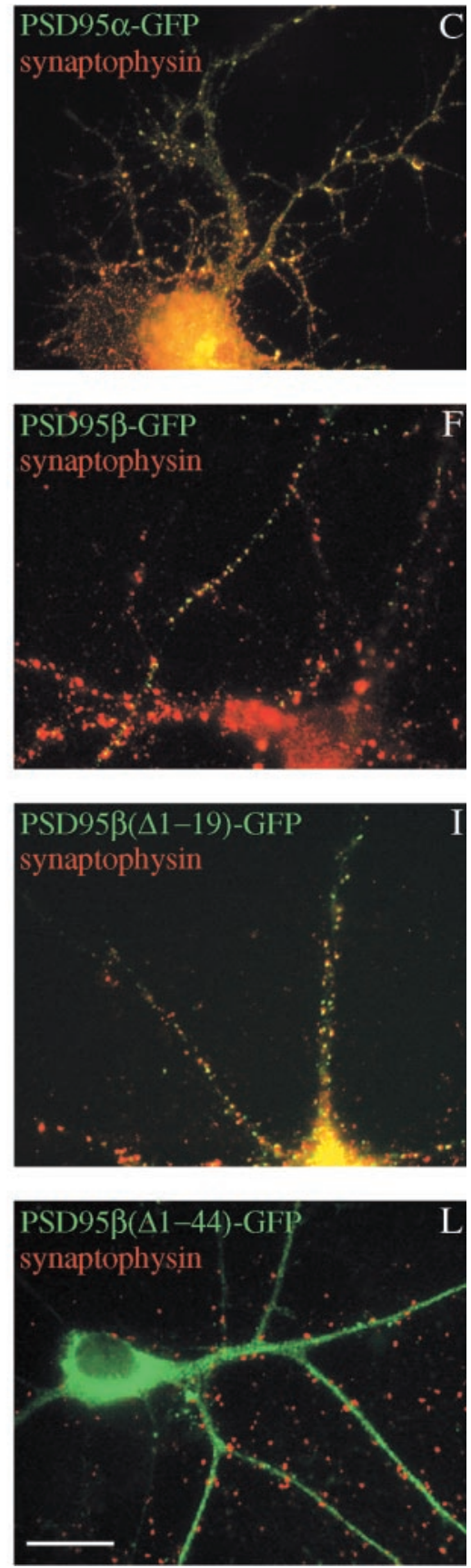

Figure 5. PSD $95 \beta$ and PSD95 $\alpha$ synaptically cluster in primary hippocampal neurons. Constructs encoding PSD95 $\beta$-GFP or PSD95 $\alpha-$ GFP were transfected into neurons that were then fixed and stained for synaptophysin (red). After $11-17 \mathrm{~d}$ in vitro, PSD95 $\alpha-\operatorname{GFP}(A-C)$ and PSD95 $\beta-\mathrm{GFP}(D-F)$ cluster at synaptic sites. PSD95 $\beta$-GFP lacking the N-terminal 19 residues [PSD95 $\beta(\Delta 1-19)-\mathrm{GFP}$ ] retains synaptic localization $(G-I)$, whereas deleting the N-terminal 44 residues from $[\mathrm{PSD} 95 \beta-\Delta(1-44)-\mathrm{GFP}]$ disrupts synaptic targeting $(J-L)$. Merged images are shown in panels on right $(C, F, I, L)$. Scale bar, $10 \mu \mathrm{m}$.

residues from the $\mathrm{N}$ terminus prevented binding. Deleting up to 228 residues from the $\mathrm{C}$ terminus retained binding, whereas deleting 248 residues blocked it. Therefore, the PSD95 $\beta$ binding region of Hrs comprises residues 349-500, which includes the coiled-coil domain as well as some flanking sequences (Fig. 6A).

To identify the regions of PSD95 $\beta$ that determine binding to Hrs, we performed immunoprecipitation studies. COS cells were cotransfected with constructs encoding Hrs and a GFP-tagged MAGUK, cell lysates were immunoprecipitated for GFP, and interaction with Hrs was assessed by Western blotting. These experiments showed that full-length PSD95 $\beta$ and a construct containing residues $20-53$ of PSD $95 \beta$ bind to Hrs, whereas PSD95 $\alpha$ does not (Fig. $6 B$ ). Residues $20-53$ of PSD95 $\beta$ show strong homology to the N-terminal L27 domain of SAP97. This suggested that Hrs would likely interact with SAP97. Indeed, coimmunoprecipitation shows robust interaction between Hrs and SAP97. On the other hand, SAP102 lacks an L27 domain and does not interact with Hrs (Fig. 6B). To confirm a physiological interaction between Hrs and PSD95 $\beta$, we performed immunoprecipitation studies with Hrs and PSD95-specific antibodies us- 


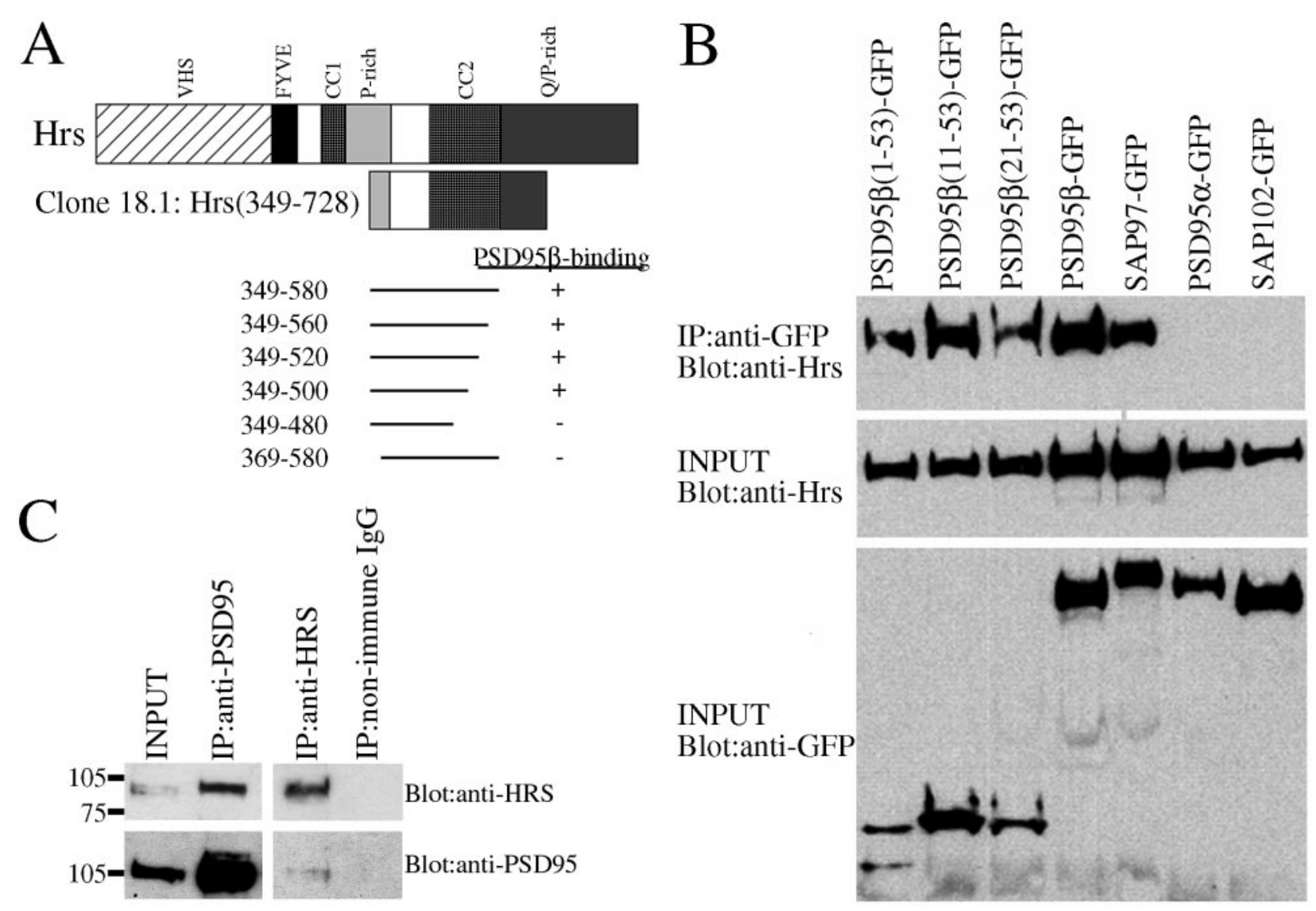

Figure 6. The L27 domains of PSD95 $\beta$ and SAP97 bind the coiled-coil domain of Hrs. $A$, Yeast two-hybrid screening with PSD95 $\beta(1-53)$ yielded a clone of Hrs containing the second coiled-coil domain and flanking sequences. Deletions of up to 228 residues from the $\mathrm{C}$ terminus of this clone preserve binding whereas removing as few as 20 residues from the $\mathrm{N}$ terminus disrupts binding. $B$, Hrs binds to PSD95 $\beta$ and SAP97 but not PSD95 $\alpha$ or SAP102. COS cells were cotransfected with constructs encoding Hrs and a GFP-tagged MAGUK protein or fragment. Cells were lysed, and immunoprecipitation with anti-GFP was followed by immunoblotting. Hrs coimmunoprecipitates with full-length PSD95 $\beta$-GFP and SAP97-GFP, as well as N-terminal GFP-fusion constructs of PSD95 $\beta$ [PSD95 $\beta(1-53)$-GFP, PSD95 $\beta(11-53)-G F P$, and PSD95 $\beta(21-53)-$ GFP], but does not interact with PSD95 $\alpha-$ GFP or SAP102-GFP (top panel). INPUT represents $10 \%$ of the COS cell lysate used for immunoprecipitation (bottom panels). $C$, Brain lysates were prepared and subjected to immunoprecipitation. Antibodies to PSD95 coimmunoprecipitated HRS, and an HRS-specific antibody coimmunoprecipitated PSD95.

ing brain homogenates. We found that antibodies to PSD95 coimmunoprecipitated HRS, and an HRS-specific antibody coimmunoprecipitated PSD95, consistent with the predicted interaction of HRS with PSD95 $\beta$ (Fig. 6C).

\section{Hrs specifically regulates trafficking of PSD95 $\beta$ and SAP97}

Because Hrs occurs on the cytosolic surface of vesicular structures in neurons (Bean et al., 2000) and regulates vesicle endocytosis (Komada and Soriano, 1999) and exocytosis (Bean et al., 1997), we wondered whether interaction with Hrs might regulate trafficking of PSD95 $\beta$. We first evaluated this in transfected COS cells. Previous studies have shown that overexpressed Hrs collapses early endosomes and induces formation of large vesicles (Bean et al., 2000; Urbé et al., 2000) that resemble abnormal endosomes of Hrs null cells (Komada and Soriano, 1999). Transfected Hrs localizes to these perinuclear endosomes, whereas PSD95 $\beta$ localizes diffusely in transfected cells (Fig. $7 A, B$ ). Cotransfection causes PSD $95 \beta$ to redistribute to the surface of large Hrs-positive vesicles (Fig. $7 C-E$ ). A PSD95 $\beta$ mutant lacking the first 19 amino acids also localizes to Hrs vesicles whereas deleting the first 44 residues of PSD95 $\beta$ prevents this colocalization (Fig. $7 F-K)$. PSD95 $\alpha$, which does not interact with Hrs remains diff use in cells cotransfected with Hrs (Fig. $7 L-N)$. Taken together with the results in Figure 5, these experiments suggest that residues 19 and 44 of PSD95 $\beta$ determine both postsynaptic targeting and association with Hrs-positive vesicles.

To determine directly whether Hrs might regulate postsynaptic targeting of PSD95, we performed immunohistochemical analysis of Hrs. In cultured neurons, endogenous Hrs occurs on large somatic vesicles and also on synaptic puncta in dendrites that partially overlap with PSD-95 (Fig. 7O-Q). Many PSD95-positive synapses are not associated with Hrs puncta. This observation is consistent with the presence of distinct pools of alternatively spliced forms of PSD95 and with the hypothesis that the interaction between Hrs and PSD95 $\beta$ is transient.

To explore possible roles for Hrs in PSD95 trafficking, we transfected hippocampal neurons with Hrs. When transfected into hippocampal neurons, Hrs induces formation of large vesicles in the soma and proximal dendrites (Fig. 8A-C) that resemble the vesicles formed by Hrs transfection in COS cells. These vesicles do not occur at synapses, because they do not colocalize with synaptophysin (Fig. $8 A-C$ ), and they resemble collapsed endosomes previously described for Hrs overexpression (Bean et al., 2000; Urbé et al., 2000). Double-labeling transfected cells 


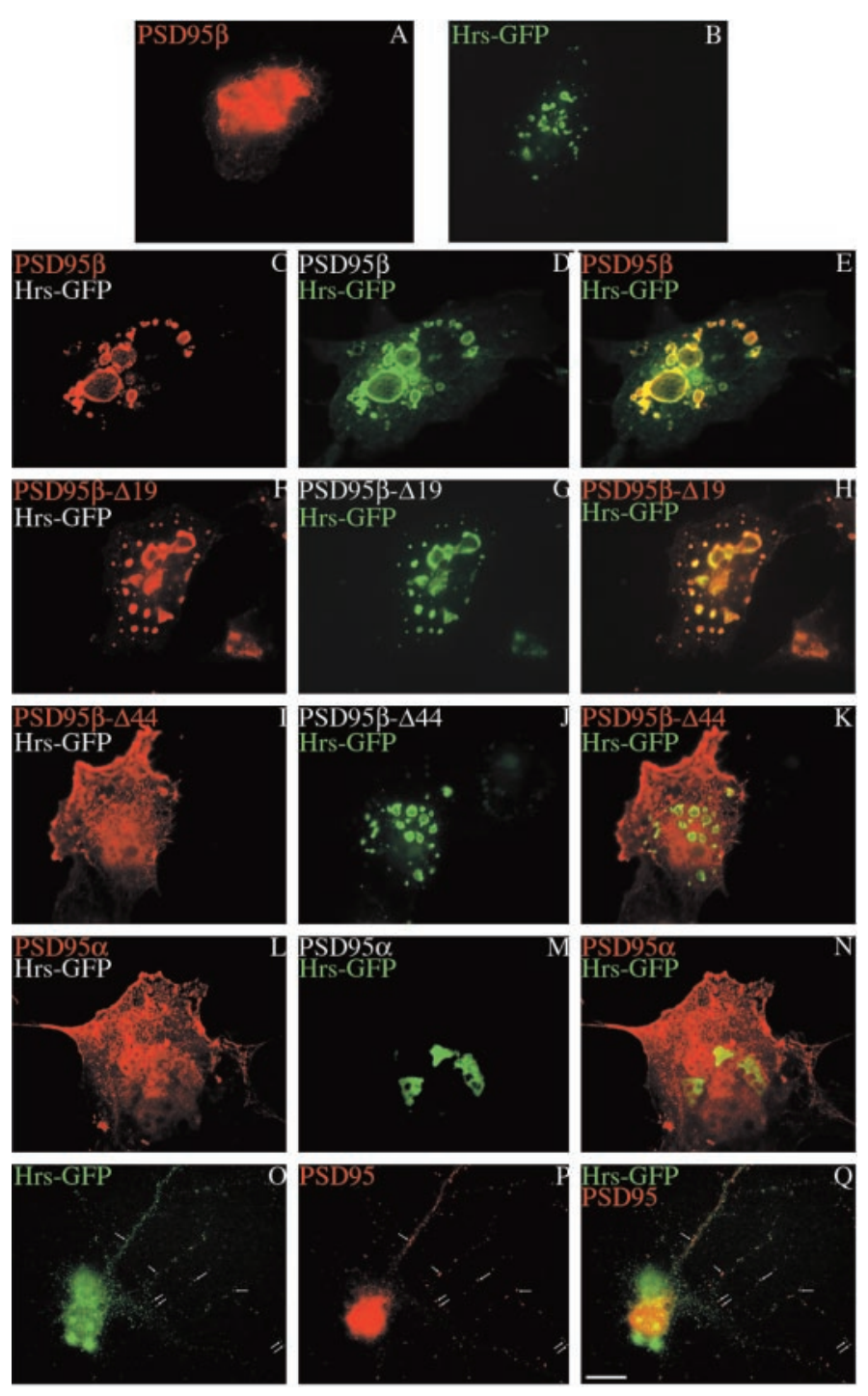

Figure 7. PSD95 $\beta$ colocalizes with Hrs in neurons and transfected COS Cells. $A$, When expressed alone in COS cells, PSD95 $\beta$ shows perinuclear and diff use cellular staining. $B$, In contrast, Hrs-GFP localizes to large intracellular vesicles. $C-E$, When cotransfected, Hrs-GFP colocalizes with PSD95 $\beta$ at these large vesicles. $F-H$, Deleting the first 19 amino acids of PSD95 $\beta$ maintains its colocalization with Hrs, whereas deleting the first 44 amino acids of PSD95 $\beta$ disrupts this colocalization $(I-K) . L-N$, PSD $95 \alpha$ does not colocalize with cotransfected Hrs-GFP. $O-Q$, Immunohistochemistry of endogenous Hrs and PSD95 shows colocalization to a subpopulation of puncta in dendrites of hippocampal neurons (arrows). Merged images are shown in $E, H, K, N$, and $Q$. Scale bar, $10 \mu \mathrm{m}$.

shows that PSD95 is recruited to Hrs-positive vesicles, but that PSD95 is also present in distal synaptic sites (Fig. 8D-F). This dual localization further supported the model that Hrs-regulated trafficking differentially influences distinct populations of endogenous PSD95. Unfortunately, the small unique $\mathrm{N}$ termini of PSD-95 $\alpha$ and PSD-95 $\beta$ were not sufficiently antigenic to generate isoform-specific antibodies (data not shown), so we could not differentially visualize endogenous PSD-95 isoforms. As an alternative approach, neurons were cotransfected with Hrs and either PSD95 $\alpha$ or PSD95 $\beta$. These experiments showed that PSD95 $\alpha$ traffics normally to the PSD despite the presence of Hrs (Fig. $8 G-I)$. On the other hand, cotransfection with Hrs blocks postsynaptic targeting of PSD95 $\beta$, which instead accumulates on large endosomal vesicles that colocalize with transfected Hrs (Fig. $8 J-L)$. Trafficking of SAP97, whose $\mathrm{N}$ terminus resembles PSD95 $\beta$, is also disrupted by Hrs overexpression, as SAP97 also accumulates on the proximal vesicles (Fig. $8 M-O$ ).

\section{DISCUSSION}

This study identifies two evolutionarily conserved isoforms of PSD95 that traffic to the PSD via distinct mechanisms. Whereas postsynaptic targeting of palmitoylated PSD95 $\alpha$ is well characterized, this work illustrates a distinct pathway for targeting PSD95 $\beta$. Also, the presence of a L27 domain at the $\mathrm{N}$ termini of PSD95 $\beta$ and SAP97 demonstrate that this recently described motif (Doerks et al., 2000) plays an important general role in assembly of postsynaptic MAGUK complexes.

Previous studies emphasized the critical role for the $\mathrm{N}$ termini of neuronal MAGUKs in cellular sorting. A pair of critical cysteine residues at the $\mathrm{N}$ terminus of PSD95 $\alpha$ was first noted to be critical for receptor clustering (Hsueh et al., 1997) and postsynaptic targeting (Craven et al., 1999). Palmitoylated cysteines are also important in clustering PSD93 (El-Husseini et al., 2000c), which also displays N-terminal splicing to form two isoforms PSD93 $\alpha$ and PSD93 $\beta$ (Brenman et al., 1996b), respectively. Although SAP102 contains a cluster of N-terminal cysteine residues (Muller et al., 1996), it is not palmitoylated, but instead its cysteines can coordinate zinc (El-Husseini et al., 2000c). Finally, SAP97, which lacks N-terminal cysteines and is not palmitoylated (El-Husseini et al., 2000c), is dependent on its N-terminal residues for sorting to the lateral membrane of epithelial cells (Wu et al., 1998).

Postsynaptic targeting of PSD95 $\beta$ relies on its N-terminal L27 motif. This domain was recently described as a small heterodimerization motif in the PDZ proteins Lin-2 and Lin-7 (Doerks et al., 2000). These proteins, together with Lin-10, form a conserved ternary protein complex that mediates receptor trafficking in epithelial cells and neurons (Butz et al., 1998; Kaech et al., 1998; Borg et al., 1999). Lin-2 contains a pair of tandem L27 domains that occur between its N-terminal calcium-calmodulin kinase motif and its first PDZ domain, whereas Lin-7 has a single L27 domain near its extreme $\mathrm{N}$ terminus (Doerks et al., 2000). Although the three dimensional structures of L27 domains are unknown, secondary structure prediction suggests that these motifs are primarily $\alpha$-helical, consistent with a coiled-coil mode for interaction (Doerks et al., 2000). Heterodimerization of L27 domains in Lin-2 and Lin-7 mediates their interaction. Similarly, the N-terminal L27 domains in PSD95 $\beta$ and SAP97 bind to CASK, the mammalian homolog of Lin-2. Previous studies have shown that SAP97 and CASK associate in vivo through interaction of their SH3 and GK domains (Nix et al., 2000). Mutations in SAP97 and CASK in mice both result in perinatal lethality associated with a cleft palate (Laverty and Wilson, 1998; Caruana and Bernstein, 2001), which may reflect interaction of these proteins during development. We find that PSD95 and CASK associate in vivo. Whether this interaction reflects binding of CASK to PSD95 $\beta$ via an L27 interaction or to either PSD95 isoform by SH3-GK interactions (Nix et al., 2000) is unclear. The functional implications of and mechanisms for PSD95 $\beta$ and SAP97 interacting with CASK, as well as how these interactions affect interactions with Hrs warrant future study.

In addition to binding to CASK, the L27 domains of PSD95 $\beta$ and SAP97 also bind to Hrs, a protein involved in endosomal sorting (Komada and Soriano, 1999). The PSD95 $\beta$ binding domain on Hrs includes a large coiled-coil region, which is consis- 

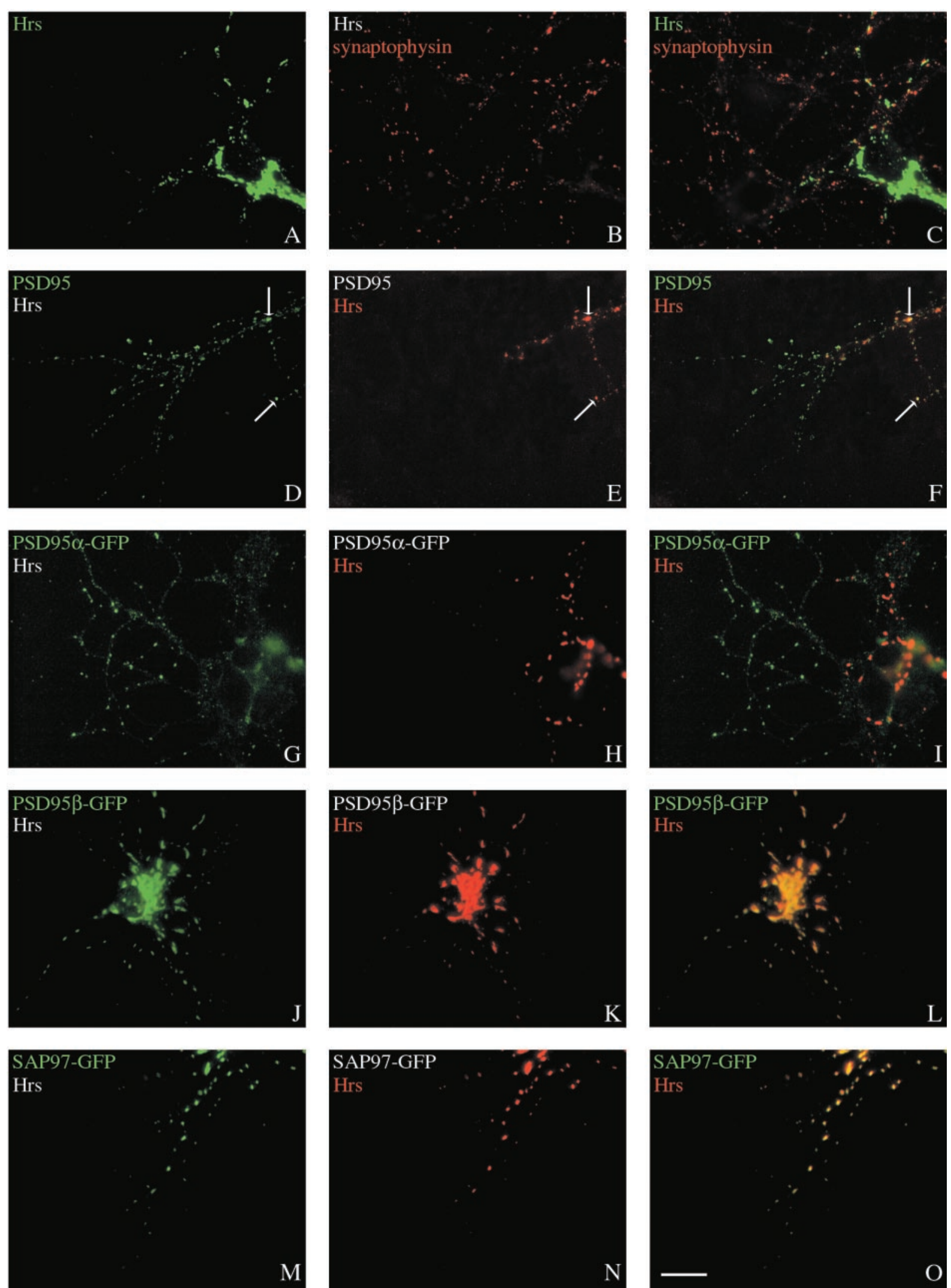

Figure 8. Hrs overexpression disrupts synaptic clustering of PSD95 $\beta$ and SAP97 in hippocampal neurons. $A-C$, Hrs expressed in hippocampal neurons (green) localizes to the surface of large vesicles in the proximal dendrites that do not overlap with synaptophysin-staining synaptic clusters $($ red $)$. $D-F$, These proximal Hrs-positive vesicles are positive for PSD95, which is also clustered at distal synaptic sites that lack Hrs. $G-I$, When cotransfected with Hrs $($ red $)$, PSD95 $\alpha$-GFP ( green) staining retains its synaptically clustered distribution. $J-L$, In contrast, Hrs disrupts synaptic clustering of PSD95 $\beta-$ GFP, which instead colocalizes with the proximal Hrs-positive vesicles. $M-O$, SAP97-GFP also accumulates at the site of Hrs-positive vesicles. Merged images are shown in $C, F, I$, and $L$. Scale bar, $10 \mu \mathrm{m}$. 
tent with a coiled coil interaction with an $\alpha$-helical L27 domain (Doerks et al., 2000). Hrs was originally identified as a tyrosine phosphorylated protein in cells stimulated with hepatocyte growth factor (Komada and Kitamura, 1995), suggesting a role in the signaling and endocytic processing of tyrosine kinase receptors (TKR). The presence of a double zinc finger domain in Hrs, which is highly similar to those in endosomal proteins EEA1 and Vps27p (Stenmark et al., 1996), and the interaction of Hrs with Eps15 of the endocytic pathway (Bean et al., 2000) suggests roles for Hrs in regulating vesicular transport. Eps15 plays an essential role in receptor-mediated endocytosis via an interaction with $\alpha$-adaptin. Hrs competes with $\alpha$-adaptin in Eps15 binding, and overexpression of Hrs inhibits transferrin endocytosis. This inhibition is abrogated by coexpression of $\alpha$-adaptin, suggesting that Hrs acts as a negative regulator of endocytosis. Indeed, targeting disruption of Hrs in mouse causes early embryonic death attributable to deficiencies in vesicular transport via endosomes (Komada and Soriano, 1999).

Another role for Hrs in vesicle trafficking was recently demonstrated by Bellen and coworkers (Lloyd et al., 2002). Mutation of Hrs in Drosophila enhances TKR signaling during development because of impaired endosomal membrane invagination and deficient formation of multiple vesicular bodies. hrs mutant flies lack lysosomal degradation of active Torso and epidermal growth factor TKRs, suggesting a critical role for Hrs in receptor downregulation (Lloyd et al., 2002). That PSD95 $\beta$ can binds to both CASK and Hrs and that Hrs has multiple partners is consistent with these coiled-coil interactions being promiscuous, akin to the promiscuity of PDZ interactions. The cellular context and relevant physiological conditions likely determine the specificity for these interactions. Indeed, $\mathrm{Hrs}$ is expressed ubiquitously (Lloyd et al., 2002), and likely plays a role in trafficking of many different proteins. In neurons, Hrs localizes to specific endosomes in somatodendritic and axonal domains (Bean et al., 2000). Overexpression of Hrs collapses these endosomes (Bean et al., 2000; Urbé et al., 2000), a phenotype similar to that seen in Hrsdeficient cells (Komada and Soriano, 1999). Our data demonstrate that PSD95 $\beta$ can bind directly to Hrs and is partially colocalized with PSD-95 in hippocampal neurons. Additionally, condensation of Hrs vesicles by overexpression selectively disrupts the trafficking of PSD95 $\beta$ but does not disturb that of PSD95 $\alpha$. Taken together, these data suggest distinct mechanisms for postsynaptic targeting of alternative PSD-95 isoforms; PSD95 $\beta$ uses coiled-coil interactions with CASK, Hrs and perhaps other proteins, whereas PSD95 $\alpha$ depends on palmitoylation and an Hrs-independent pathway.

The interactions described here may also dynamically regulate PSD95 complexes at the synapse. Recent studies indicate that the PSD is not static but rather displays robust structural plasticity (Fischer et al., 1998; Marrs et al., 2001). Furthermore, rapid changes in synaptic expression of AMPA receptors through regulated exocytosis and endocytosis underlies aspects of activitydependent synaptic plasticity including long-term potentiation and long-term depression, respectively (Malenka and Nicoll, 1999; Malinow et al., 2000). PSD95 appears to play a central role in synaptic plasticity as overexpression of PSD95 selectively enhances synaptic AMPA receptors (El-Husseini et al., 2000b) and targeted mutation of PSD95 enhances long-term potentiation and eliminates long-term depression (Migaud et al., 1998). This regulation of AMPA receptors by PSD95 likely involves stargazin, an AMPA receptor trafficking protein that interacts with PDZ domains of PSD95 (Chen et al., 2000).
How might PSD95-stargazin-dependent trafficking of AMPA receptors be regulated by synaptic strength? The intramolecular SH3-GK domain interaction represents a potential regulatory site (McGee and Bredt, 1999; Shin et al., 2000; McGee et al., 2001; Tavares et al., 2001). For PSD95 $\alpha$, dynamic and reversible changes in palmitoylation provide an important mechanism for regulating synaptic AMPA receptors (El-Husseini et al., 2002). By analogy, the L27 domains of PSD95 $\beta$ and SAP97 may provide sites for regulation. One intriguing mechanism involves TKRs, which robustly phosphorylate Hrs (Komada and Kitamura, 1995) and are implicated in LTP (Kang and Schuman, 1995). Future studies of mice with conditional mutation of Hrs in neurons or with specific targeted mutations of PSD95 $\alpha$ or PSD95 $\beta$ will help define the roles for these interactions in synapse assembly and plasticity.

\section{REFERENCES}

Bean AJ, Seifert R, Chen YA, Sacks R, Scheller RH (1997) Hrs-2 is an ATPase implicated in calcium-regulated secretion. Nature 385:826-829

Bean AJ, Davanger S, Chou MF, Gerhardt B, Tsujimoto S, Chang Y (2000) Hrs-2 regulates receptor-mediated endocytosis via interactions with Eps15. J Biol Chem 275:15271-15278.

Borg J-P, Lõpez-Figueroa MO, de Taddèo-Borg M, Kroon DE, Turner RS, Watson SJ, Ben Margolis B (1999) Molecular analysis of the X11-mLin-2/CASK complex in brain. J Neurosci 19:1307-1316.

Brenman JE, Chao DS, Gee SH, McGee AW, Craven SE, Santillano DR, Huang F, Xia H, Peters MF, Froehner SC, Bredt DS (1996a) Interaction of nitric oxide synthase with the postsynaptic density protein PSD-95 and $\alpha-1$ syntrophin mediated by PDZ motifs. Cell 84:757-767.

Brenman JE, Christopherson KS, Craven SE, McGee AW, Bredt DS (1996b) Cloning and characterization of postsynaptic density 93 (PSD93), a nitric oxide synthase interacting protein. J Neurosci 16:7407-7415.

Brenman JE, Topinka JR, Cooper EC, McGee Cooper, Rosen J, Milroy T, Ralston HJ, Bredt DS (1998) Localization of postsynaptic density-93 to dendritic microtubules and interaction with microtubuleassociated protein 1A. J Neurosci 18:8805-8813.

Butz S, Okamoto M, Südhof TC (1998) A tripartite protein complex with the potential to couple synaptic vesicle exocytosis to cell adhesion in brain. Cell 94:773-782.

Caruana G, Bernstein A (2001) Craniofacial dysmorphogenesis including cleft palate in mice with an insertional mutation in the discs large gene. Mol Cell Biol 21:1475-1483.

Chen L, Chetkovich DM, Petrailia R, Sweeney Petrailia, Kawaski Y, Wenthold R, Bredt DS, Nicoll RA (2000) Stargazin mediates synaptic targeting of AMPA receptors by two distinct mechanisms. Nature 408:936-943.

Cho KO, Hunt CA, Kennedy MB (1992) The rat brain postsynaptic density fraction contains a homolog of the Drosophila discs-large tumor suppressor protein. Neuron 9:929-942.

Craven SE, Bredt DS (2000) Synaptic targeting of the postsynaptic density protein PSD-95 mediated by a tyrosine-based trafficking signal. J Biol Chem 275:20045-20051.

Craven SE, Husseini AE, Bredt DS (1999) Synaptic targeting of the postsynaptic density protein PSD-95 mediated by lipid and protein motifs. Neuron 22:497-509.

Doerks T, Bork P, Kamberov E, Makarova O, Muecke S, Margolis B (2000) L27, a novel heterodimerization domain in receptor targeting proteins Lin-2 and Lin-7. Trends Biochem Sci 25:317-318.

El-Husseini AE, Craven SE, Chetkovich DM, Firestein BL, Schnell E, Aoki C, Bredt DS (2000a) Dual palmitoylation of PSD-95 mediates its vesiculotubular sorting, postsynaptic targeting, and ion channel clustering. J Cell Biol 148:159-172.

El-Husseini AE, Schnell E, Chetkovich DM, Nicoll RA, Bredt DS (2000b) PSD-95 involvement in maturation of excitatory synapses. Science 290:1364-1368.

El-Husseini AE, Topinka JR, Lehrer-Graiwer JE, Firestein BL, Craven SE, Aoki C, Bredt DS (2000c) Ion channel clustering by membraneassociated guanylate kinases. Differential regulation by $\mathrm{N}$-terminal lipid and metal binding motifs. J Biol Chem 275:23904-23910.

El-Husseini AE, Schnell E, Dakoji S, Sweeney N, Zhou Q, Prange O, Gauthier-Campbell C, Aguilera-Moreno A, Nicoll RA, Bredt DS (2002) Synaptic strength regulated by palmitate cycling on PSD-95. Cell 108:849-863.

Fischer M, Kaech S, Knutti D, Matus A (1998) Rapid actin-based plasticity in dendritic spines. Neuron 20:847-854.

Garner CC, Nash J, Huganir RL (2000) PDZ domains in synapse assembly and signalling. Trends Cell Biol 10:274-280. 
Guan B, Hartmann B, Kho YH, Gorczyca M, Budnik V (1996) The Drosophila tumor suppressor gene, dlg, is involved in structural plasticity at a glutamatergic synapse. Curr Biol 6:695-706.

Hanada T, Lin L, Tibaldi E V, Reinherz EL, Chishti AH (2000) GAKIN, a novel kinesin-like protein associates with the human homologue of the Drosophila discs large tumor suppressor in T lymphocytes. J Biol Chem 275:28774-28784.

Hata Y, Butz S, Sudhof TC (1996) CASK: a novel dlg/PSD95 homolog with an N-terminal calmodulin-dependent protein kinase domain identified by interaction with neurexins. J Neurosci 16:2488-2494.

Hsueh YP, Kim E, Sheng M (1997) Disulfide-linked head-to-head multimerization in the mechanism of ion channel clustering by PSD-95. Neuron 18:803-814.

Irie M, Hata Y, Takeuchi M, Ichtchenko K, Toyoda A, Hirao K, Takai Y, Rosahl TW, Sudhof TC (1997) Binding of neuroligins to PSD-95. Science 277:1511-1515.

Jo K, Derin R, Li M, Bredt DS (1999) Characterization of MALS/ Velis-1, -2, and -3: a family of mammalian LIN-7 homologs enriched at brain synapses in association with the postsynaptic density-95/NMDA receptor postsynaptic complex. J Neurosci 19:4189-4199.

Kaech S, Ludin B, Matus A (1996) Cytoskeletal plasticity in cells expressing neuronal microtubule-associated proteins. Neuron 17: 1189-1199.

Kaech SM, Whitfield CW, Kim SK (1998) The LIN-2/LIN-7/LIN-10 complex mediates basolateral membrane localization of the $C$. elegans EGF receptor LET-23 in vulval epithelial cells. Cell 94:761-771.

Kang H, Schuman EM (1995) Long-lasting neurotrophin-induced enhancement of synaptic transmission in the adult hippocampus. Science 267:1658-1662.

Kennedy MB (2000) Signal-processing machines at the postsynaptic density. Science 290:750-754.

Kim E, Sheng M (1996) Differential $\mathrm{K}^{+}$channel clustering activity of PSD-95 and SAP97, two related membrane-associated putative guanylate kinases. Neuropharmacology 35:993-1000.

Kim E, Niethammer M, Rothschild A, Jan YN, Sheng M (1995) Clustering of Shaker-type $\mathrm{K}^{+}$channels by direct interaction with the PSD-95/SAP90 family of membrane-associated guanylate kinases. Nature 378:85-88.

Kim E, Cho K-O, Rothschild A, Sheng M (1996) Heteromultimerization and NMDA receptor clustering activity of chapsyn-110, a novel member of the PSD-95 family of synaptic proteins. Neuron 17:103-113.

Kim E, Naisbitt S, Hsueh YP, Rao A, Rothschild A, Craig AM, Sheng M (1997) GKAP, a novel synaptic protein that interacts with the guanylate kinase-like domain of the PSD-95/SAP90 family of channel clustering molecules. J Cell Biol 136:669-678.

Kistner U, Wenzel BM, Veh RW, Cases-Langhoff C, Garner AM, Appeltauer U, Voss B, Gundelfinger ED, Garner CC (1993) SAP90, a rat presynaptic protein related to the product of the Drosophila tumor suppressor gene dlg-A. J Biol Chem 268:4580-4583.

Komada M, Kitamura N (1995) Growth factor-induced tyrosine phosphorylation of Hrs, a novel 115-kilodalton protein with a structurally conserved putative zinc finger domain. Mol Cell Biol 15:6213-6221.

Komada M, Soriano P (1999) Hrs, a FYVE finger protein localized to early endosomes, is implicated in vesicular traffic and required for ventral folding morphogenesis. Genes Dev 13:1475-1485.

Kornau H-C, Schenker LT, Kennedy MB, Seeburg PH (1995) Domain interaction between NMDA receptor subunits and the postsynaptic density protein PSD-95. Science 269:1737-1740.

Kornau H-C, Seeburg PH, Kennedy MB (1997) Interaction of ion channels and receptors with PDZ domains. Curr Opin Neurobiol 7:368-373.

Laverty HG, Wilson JB (1998) Murine CASK is disrupted in a sexlinked cleft palate mouse mutant. Genomics 53:29-41.

Lee SH, Sheng M (2000) Development of neuron-neuron synapses. Curr Opin Neurobiol 10:125-131.

Lloyd TE, Atkinson R, Wu MN, Zhou Y, Pennetta G, Bellen HJ (2002) Hrs regulates endosome membrane invagination and tyrosine kinase receptor signaling in Drosophila. Cell 108:261-269.

Malenka RC, Nicoll RA (1999) Long-term potentiation-a decade of progress? Science 285:1870-1874.

Malinow R, Mainen ZF, Hayashi Y (2000) LTP mechanisms: from silence to four-lane traffic. Curr Opin Neurobiol 10:352-357.

Marrs GS, Green SH, Dailey ME (2001) Rapid formation and remod- eling of postsynaptic densities in developing dendrites. Nat Neurosci 4:1006-1013.

McGee AW, Bredt DS (1999) Identification of an intramolecular interaction between the SH3 and guanylate kinase domains of PSD-95. J Biol Chem 274:17431-17436.

McGee AW, Dakoji SR, Olsen O, Bredt DS, Lim WA, Prehoda KE (2001) Structure of the SH3-guanylate kinase module from PSD-95 suggests a mechanism for regulated assembly of MAGUK scaffolding proteins. Mol Cell 8:1291-1301.

Migaud M, Charlesworth P, Dempster M, Webster LC, Watabe AM Makhinson M, He Y, Ramsay MF, Morris RG, Morrison JH, O'Dell TJ, Grant SG (1998) Enhanced long-term potentiation and impaired learning in mice with mutant postsynaptic density-95 protein. Nature 396:433-439.

Muller BM, Kistner U, Veh RW, Cases-Langhoff C, Becker B, Gundelfinger ED, Garner CC (1995) Molecular characterization and spatial distribution of SAP97, a novel presynaptic protein homologous to SAP90 and the Drosophila discs-large tumor suppressor protein. J Neurosci 15:2354-2366.

Muller BM, Kistner U, Kindler S, Chung WK, Kuhlendahl S, Fenster SD, Lau L-F, Veh RW, Huganir RL, Gundelfinger ED, Garner CC (1996) SAP102, a novel postsynaptic protein that interacts with NMDA receptor complexes in vivo. Neuron 17:255-265.

Nix SL, Chishti AH, Anderson JM, Walther Z (2000) hCASK and hDlg associate in epithelia, and their Src homology 3 and guanylate kinase domains participate in both intramolecular and intermolecular interactions. J Biol Chem 275:41192-41200.

Rao A, Kim E, Sheng M, Craig AM (1998) Heterogeneity in the molecular composition of excitatory postsynaptic sites during development of hippocampal neurons in culture. J Neurosci 18:1217-1229.

Sala C, Piech V, Wilson NR, Passafaro M, Liu G, Sheng M (2001) Regulation of dendritic spine morphology and synaptic function by Shank and Homer. Neuron 31:115-130.

Sassoon D, Rosenthal N (1993) Detection of messenger RNA by in situ hybridization. Methods Enzymol 225:384-404.

Scheiffele P, Fan J, Chioh J, Fetter R, Serafini T (2000) Neuroligin expressed in nonneuronal cells triggers presynaptic development of contacting axons. Cell 101:657-669.

Sheng M, Sala C (2001) PDZ domains and the organization of supramolecular complexes. Annu Rev Neurosci 24:1-29.

Shin H, Hsueh YP, Yang FC, Kim E, Sheng M (2000) An intramolecular interaction between Src homology 3 domain and guanylate kinaselike domain required for channel clustering by postsynaptic density-95/ SAP90. J Neurosci 20:3580-3587.

Stathakis DG, Hoover KB, You Z, Bryant PJ (1997) Human postsynaptic density-95 (PSD95): location of the gene (DLG4) and possible function in nonneural as well as in neural tissues. Genomics 44:71-82.

Stenmark H, Aasland R, Toh BH, D'Arrigo A (1996) Endosomal localization of the autoantigen EEA1 is mediated by a zinc-binding FYVE finger. J Biol Chem 271:24048-24054.

Takeuchi M, Hata Y, Hirao K, Toyoda A, Irie M, Takai Y (1997) SAPAPs. A family of PSD-95/SAP90-associated proteins localized at postsynaptic density. J Biol Chem 272:11943-11951.

Tavares GA, Panepucci EH, Brunger AT (2001) Structural characterization of the intramolecular interaction between the $\mathrm{SH} 3$ and guanylate kinase domains of PSD-95. Mol Cell 8:1313-1325.

Thomas U, Ebitsch S, Gorczyca M, Koh YH, Hough CD, Woods D, Gundelfinger ED, Budnik V (2000) Synaptic targeting and localization of discs-large is a stepwise process controlled by different domains of the protein. Curr Biol 10:1108-1117.

Tomita S, Nicoll RA, Bredt DS (2001) PDZ protein interactions regulating glutamate receptor function and plasticity. $J$ Cell Biol 153:F19-F24.

Topinka JR, Bredt DS (1998) N-terminal palmitoylation of PSD-95 regulates association with cell membranes and interaction with $\mathrm{K}^{+}$channel, Kv1.4. Neuron 20:125-134.

Urbé S, Mills IG, Stenmark H, Kitamura N, Clague MJ (2000) Endosomal localization and receptor dynamics determine tyrosine phosphorylation of hepatocyte growth factor-regulated tyrosine kinase substrate. Mol Cell Biol 20:7685-7692.

Wu H, Reuver SM, Kuhlendahl S, Chung WJ, Garner CC (1998) Subcellular targeting and cytoskeletal attachment of SAP97 to the epithelial lateral membrane. J Cell Sci 111:2365-2376. 